\title{
A copa do mundo Fifa na África do Sul/2010 - como foi a experiência e o que podemos aprender com ela?
}

\author{
Wanderley Marchi Júnior* \\ Chris Bolsmann** \\ Bárbara Schausteck de Almeida*** \\ Juliano de Souza****
}

\begin{abstract}
Resumo: Neste ensaio pretendemos problematizar algumas lógicas sociais não explícitas que se articulam ao domínio de realização da Copa do Mundo FIFA. Para tanto, privilegiamos como recorte analítico a edição de 2010 deste evento, de modo a desvelarmos algumas das retóricas e ações estratégicas que permearam o contexto de sua realização na África do Sul. Com base em dados obtidos na literatura acadêmica e mídia, buscamos apresentar que as motivações para o evento se baseavam em discursos desenvolvimentistas por parte tanto da FIFA quanto das elites locais sul-africanas visando o convencimento e apoio de diferentes grupos sociais. Entretanto, as consequências não foram necessariamente aquelas prometidas, sendo essas instituições as reais beneficiadas em seus interesses econômicos e políticos. Nesse ponto, argumentamos que a sociedade brasileira pode e deve aprender com essa experiência para avaliar de forma crítica os motivos menos aparentes de sediar eventos desse porte.
\end{abstract}

Palavras-chave: Megaeventos. Futebol. Copa do Mundo FIFA. África do Sul 2010.

\footnotetext{
*Professor dos Programas de Pós-Graduação em Educação Física e Sociologia na Universidade Federal do Paraná (UFPR). Professor convidado da West Virginia University (Estados Unidos)-marchijr@ufpr.br

**Professor doutor na Aston University (Inglaterra) e professor convidado na University of Johannesburg (África do Sul) - c.h.bolsmann@aston.ac.uk

***Aluna de doutorado no Programa de Pós-Graduação em Educação Física da Universidade Federal do Paraná (UFPR) - barbaracwb@gmail.com

****Aluno de doutorado no Programa de Pós-Graduação em Educação Física da Universidade Federal do Paraná (UFPR) e professor na Universidade Estadual do Centro-Oeste (UNICENTRO) - julianoedf@yahoo.com.br
} 


\section{INTRODUÇÃo}

No ano de 2010, a África do Sul sediou a Copa do Mundo FIFA, numa experiência inédita expressa na realização deste evento pela primeira vez, desde sua criação em 1930, em um país pertencente ao continente africano. A opção pela África, segundo defendem os discursos institucionais, se deu basicamente por conta da implantação do princípio do rodízio entre continentes, que curiosamente iniciou em 2010 e será abandonado em 2014 na oportunidade em que o Brasil, pela segunda vez na história, abrigará o evento (FIFA, 2007d). É importante notar que muito embora esse sistema de rodízio se faça crer socialmente como uma iniciativa democrática e de difusão do futebol e do fair play pelo mundo, não podemos negar que, por detrás dessa conjuntura, reside o desejo de expandir os mercados de consumo e garantir significativo retorno aos parceiros comerciais da FIFA, a exemplo do que também ocorre para o Comitê Olímpico Internacional (TAVARES, 2011, DAMO, 2012, MASCARENHAS, 2012).

No bojo dessa análise, convém inicialmente chamar atenção para a visibilidade global de eventos desse porte através da mídia televisionada, até porque é a intenção de veicular determinadas imagens por via dos megaeventos que anima as tomadas de posição tanto dos países-sede como das grandes corporações, que visam, sobretudo, expandir seus mercados através do "complexo global esporte-mídia-turismo" (NAURIGHT, 2004, p. 1334, tradução nossa). Concomitantemente a esse primeiro objetivo, é oportuno também salientar que imagens desejadas são projetadas pelas sedes e as contradições obscurecidas. Se, por um lado então, os megaeventos são vistos como catalisadores do desenvolvimento urbano (HAFERBURG, 2011), por outro lado, elites políticas e demais partes interessadas reproduzem esse discurso cujo efeito maior é mascarar quem são os mais beneficiados pelos megaeventos esportivos, especialmente a FIFA e as grandes corporações (SUGDEN; TOMLINSON, 1998, JENNINGS, 2007, DAMO, 2012, REIS, 2012).

Movimento, Porto Alegre, v. 20, n. 2, p. 711-733, abr./jun. de 2014. 
Cabe também lembrar que em países considerados como "periféricos", tais como são rotulados a África do Sul, o Brasil, a China e a Índia, dentre outros, os grandes eventos esportivos assumem uma lógica de gerenciamento intercalada com fortes sentimentalismos e emoções que talvez extrapolem os limites do bom-senso quando comparados com outros países. De uma maneira geral, as razões aparentes para sediar tais eventos se sustentam com base em uma crença no desenvolvimento e na modernização, num discurso generalista e por isso bastante abstrato, atrelado ao "princípio" de que os megaeventos supostamente trazem significativos impactose "legados"paradiversossetores da sociedade (BLACK; VAN DER WESTHUIZEN, 2004, DAMO, 2012). Essa estratégia além de fundamentar o imaginário social é defendida por elites políticas, assim como pelas grandes empresas feitas parceiras estratégicas das organizações mundiais que se colocam à frente do esporte-espetáculo. Essa movimentação discursiva, por sua vez, é crucial em termos de efetividade promocional e estratégia identitárias desses eventos, gerando e fomentando uma série de sentimentos de pertencimento, reconhecimento, distinção e socialização (BURBANK; ANDRANOVICH; HEYING, 2001, MIAH; GARCÍA, 2012).

No lastro, portanto, dessas considerações tecidas é que pretendemos problematizar ao longo deste ensaio aquelas lógicas sociais não explícitas que se articulam ao domínio de realização da Copa do Mundo FIFA. Para tanto, privilegiamos como recorte analítico, num primeiro momento, a edição de 2010 deste evento, de modo a desvelarmos algumas das retóricas e ações estratégicas que permearam o contexto de realização da Copa do Mundo FIFA na África do Sul. Em seguida, procuramos argumentar que a sociedade brasileira pode e deve aprender com a experiência da África do Sul no propósito de avaliar com cautela o discurso dos "legados" dos megaeventos e entender de uma forma mais crítica e reflexiva os reais motivos de sediar eventos desse porte no país. Com vistas a alavancar essa discussão, nos valemos de uma série de dados provenientes da mídia sul-africana e internacional, assim

Movimento, Porto Alegre, v. 20, n. 2, p. 711-733, abr.jun. de 2014. 
como de documentos oficiais da FIFA, além de estudos acadêmicos publicados no tocante à referida temática.

\section{A experiência da África do Sul 2010}

Antes da libertação de Nelson Mandela da prisão em fevereiro de 1990, autoridades do futebol sul-africano se encontraram com representantes do Congresso Nacional Africano (ANC) na cidade de Lusaka, Zâmbia em 1988 (ALEGI; BOLSMANN, 2010). Nos primeiros encontros, foi encorajada a criação de uma unidade a partir das diferentes organizações do futebol na África do Sul. A manutenção do boicote esportivo foi confirmada e entendia-se que a readmissão à FIFA só poderia acontecer após a abolição do apartheid. A FIFA foi oficialmente informada sobre esses desenvolvimentos e se encontrou com alguns oficiais sul-africanos em 1989 que "não-oficialmente" davam suporte à tal unidade (ALEGI; BOLSMANN, 2010, p. 15).

Durante o ano de 1990, os oficiais do futebol se encontraram em diversas ocasiões e formaram a Associação Sul-Africana de Futebol (SAFA). Em setembro de 1991, a SAFA foi readmitida pela Confederação Africana de Futebol (CAF) com algumas condições. Em fevereiro do ano seguinte, a CAF recomendou à FIFA a readmissão da SAFA por essa entidade mundial, o que ocorreu em 3 de julho de 1992. Quatro dias depois, a África do Sul participou de seu primeiro jogo internacional na cidade de Durban. Mais tarde, naquele mesmo ano, o então presidente da FIFA João Havelange sugeriu que a África do Sul poderia sediar uma futura Copa do Mundo (ALEGI, 2001).

Membros executivos da SAFA participaram da Copa do Mundo de 1994 nos Estados Unidos e em setembro daquele ano escreveram a FIFA que "antecipadamente apresentavam [sua] candidatura... [já que] eram o mais qualificado país da África para sediar a Copa do Mundo" no ano de 2006 (FIFA, 1994). No entanto, compete-nos alertar que a candidatura foi somente apresentada formalmente no ano de 1998, quando então outros

Movimento, Porto Alegre, v. 20, n. 2, p. 711-733, abr.jun. de 2014. 
países, tais como Alemanha, Inglaterra, Brasil e Marrocos, também se posicionaram como concorrentes. O comitê executivo da FIFA decidiu a sede de 2006 em circunstâncias controversas em julho de 2000 (BOLSMANN, 2012).

O presidente da Associação de Futebol da Oceania, Charles Dempsey, foi instruído pela sua associação a votar pela África do Sul para que a Inglaterra fosse eliminada. Ele se absteve e a Alemanha venceu a candidatura sul-africana por 12 votos a 11 . O presidente do país Thabo Mbeki afirmou que aquele "era um dia trágico para a África... [mas] que na próxima vez nós venceremos" (FOR THE GOOD..., 2000). A SAFA recorreu da decisão e preparou uma documentação para contestá-la na Alta Corte de Zurique (FOR THE GOOD..., 2000). Em agosto de 2000, a FIFA anunciou o princípio de rodízio para as futuras sedes da Copa do Mundo, sendo a África o continente que sediaria o torneio de 2010. Como resultado, as autoridades sul-africanas desistiram do recurso sobre a decisão de 2006, quando perceberam que poderiam ter uma grande possibilidade de eleger-se sede para o ano de 2010. Entretanto, a competição não foi simples, pois havia o interesse do Marrocos, já candidato para anos anteriores (1994, 1998 e 2006).

Já na candidatura de 2006, os dirigentes sul-africanos argumentavam que "a vez da África chegou" (BOLSMANN, 2012). Além disso, uma retórica pan-africana foi evidente em 2006, interligada com imagens estereotípicas da natureza africana. Para Alegi (2001), a candidatura de 2006 melhorou o posicionamento do país internacionalmente, o que pôde colaborar para o turismo internacional e para invocar o orgulho nacional. Nos livros de candidatura de 2006 e 2010, os organizadores enfatizaram o pan-africanismo envolto em retóricas de desenvolvimento social e de modernização. A África do Sul foi apresentada como uma democracia nova e estável, com infraestrutura capaz de sediar o evento. Significativamente, os organizadores sul-africanos deixaram claro que sediar a Copa do Mundo no país ofereceria à FIFA recompensas financeiras que poderiam ser acumuladas num contexto seguro (BOLSMANN, 2012). No caso das

Movimento, Porto Alegre, v. 20, n. 2, p. 711-733, abr.jun. de 2014. 
candidaturas do Marrocos e África do Sul, ambos os países se projetaram como sendo "o portão para a África" e "o verdadeiro representante africano" (CORNELISSEN, 2004), em que eles seriam capazes de mostrar o continente africano para os mercados europeu e norte-americano (ALEGI, 2001, CORNELISSEN, 2004, CORNELLISSEN; SWART, 2006, BOLSMANN, 2010).

A imprensa sul-africana sugeriu que a candidatura era "verdadeiramente africana" e que os benefícios poderiam ser sentidos não somente pela África do Sul, bem como por seus vizinhos (SOWETAN, 2004). A votação para a sede de 2010 não teve o resultado como muitos sul-africanos imaginavam. Embora a África do Sul tenha vencido a candidatura do Marrocos por 14 votos a 10, alegou-se que os quatro representantes da CAF no Comitê Executivo da FIFA acabaram votando para o Marrocos. A imprensa sul-africana saudou a decisão da FIFA, afirmando que a eleição foi "um voto de confiança na habilidade dos sul-africanos em particular e dos africanos em geral” (SOWETAN, 2004).

Inúmeros comentadores levantaram preocupações em sediar a Copa do Mundo FIFA na África do Sul e os organizadores locais tiveram que agir contra a cobertura midiática negativa e estereótipos racistas em relação à habilidade dos africanos de forma geral a sediarem o evento (TOMLINSON; BASS; PILLAY, 2009, JENNINGS, 2007, DARBY, 2002). Em 2000, Bobby Charlton, um membro do Comitê de Candidatura da Inglaterra para a Copa do Mundo FIFA de 2006 sugeriu que o evento realizado em um "[...] país na hora errada [...] pode ser um desastre" (COLONIAL..., 2000), enquanto o seu colega alemão Franz Beckenbauer levantou preocupações semelhantes sugerindo que a organização sulafricana foi "assolada por grandes problemas [...] problemas africanos" (BBC, 2006). Estas preocupações foram concretizadas em referência aos níveis de criminalidade na África do Sul e do ritmo lento da construção de estádios e desenvolvimento de infraestrutura (GLANVILLE, 2010, KORTH; ROLFES, 2010, PANK, 2008).

Movimento, Porto Alegre, v. 20, n. 2, p. 711-733, abr.jun. de 2014. 
Estas preocupações foram agravadas quando 62 imigrantes africanos e refugiados foram mortos em violência xenófoba em 2008 (DESAI; VAHED, 2010). O ataque contra a seleção nacional do Togo durante o Campeonato Africano das Nações em Cabinda/ Angola em janeiro de 2010 levantou preocupações adicionais na imprensa britânica em particular (ELLIS, 2010, LEWIS, 2010). Em abril de 2010, o líder da extrema-direita do grupo separatista Afrikaner Weerstandsbeweging (AWB), Eugène Terre Blanche foi assassinado. Em função dessa conjuntura, os tablóides britânicos sugeriram que uma "guerra de raça" havia sido declarada na África do Sul (HUGHES, 2010). Estes incidentes, por sua vez, exacerbaram as análises exógenas de realização de uma Copa do Mundo FIFA em um país africano tido como potencialmente inseguro. Cabe notarmos que os problemas de crime e desigualdade sul-africanos foram extensivamente reportados na mídia internacional, enquanto a FIFA e os organizadores sul-africanos combatiam essas notícias ao focalizar nos objetivos desenvolvimentistas da Copa do Mundo. Não por acaso, inclusive, o governo sul-africano afirmou que o torneio viria a "acelerar o desenvolvimento e crescimento do país" (CORNELISSEN; BOB; SWART, 2011a, p. 305).

Apesar de todas essas alegações, o torneio foi anunciado como um sucesso. Blatter, presidente da FIFA exclamou: "A África provou que pode organizar uma Copa do Mundo" e que as percepções sobre a África "mudaram" (NTLOKO, 2010). O The Times da Grã-Bretanha escreveu que o evento "foi um triunfo para a África do Sul" e que este país "realizou um dos mais impecáveis torneios na história”. O The Economist (SOUTH AFRICA..., 2010) chamou o evento de "triunfo". O jornal de Johanesburgo, a Saturday Star, afirmou que a África do Sul era "uma nação de classe mundial", enquanto o The Sunday Independent escreveu que era o evento era "um salto gigante para a África". O editor Makhudu Sefara do jornal The Sunday Independent chegou a afirmar que a Copa do Mundo FIFA teria sido "momento de maior orgulho da África". O discurso dos organizadores, da imprensa e de muitos comentaristas sociais enfatizava, acima de tudo, que o "legado social" do evento havia sido positivo. No entanto, considerando que os megaeventos

Movimento, Porto Alegre, v. 20, n. 2, p. 711-733, abr.jun. de 2014. 
esportivos estão envoltos em históricos de "consentimentos manufaturados", em que a mídia adota uma visão de apoio aos discursos oficiais de políticos e organizações esportivas e que, em oposição, críticas e resistências aos megaeventos esportivos são suprimidos (HORNE, 2007, LENSKYJ, 1996; 2000; 2002; 2004), esses dados divulgados precisam ser analisados cuidadosamente.

Na preparação do evento de 2010, o documentário televisivo escrito e dirigido pelo australiano Craig Tanner intitulado Fahrenheit 2010, colocou questões críticas sobre a alocação de recursos no contexto de extrema desigualdade social e não foi ao ar na televisão sul-africana. A rede pública de televisão South African Broadcasting Corporation (SABC) argumentou que seu trabalho era "promover a Copa do Mundo" e o canal de televisão ETV sugeriu que o documentário "não era apropriado para o público sul-africano" (MOYO, 2010). O documentário tratava de alguns temas polêmicos, apontados também em outras mídias, como as pessoas desabrigadas que foram transferidas do centro da cidade para alojamento temporário em Blikkiesdorp na Cidade do Cabo (SMITH, 2010). Em Nelspruit, a construção do Estádio Mbombela foi concluída sob um contexto de assassinato, corrupção e irregularidades no concurso (TOLSI, 2010, MCKINLEY, 2011).

O custo de desenvolvimento de infraestrutura e construção de estádios foram estimados em 7,3 bilhões dólares acima das estimativas iniciais de US\$ 330 milhões em 2003 (SOUTH AFRICA..., 2010). A construção de cinco novos estádios bem como a reforma de outros cinco na África do Sul foram financiados principalmente pelo Estado, ao contrário do que ocorreu na Alemanha em 2006, onde empresas privadas contribuíram com quantidades substanciais para os custos de construção (HAFERBURG, 2011). Estima-se, além disso, que o Estado sulafricano tenha gasto em excesso 5 bilhões de dólares em projetos de infraestrutura, tais como transporte e fornecimento de energia (CORNELISSEN; BOB; SWART, 2011b). É oportuno, todavia, ressaltar que os estádios permanecem subutilizados no cenário esportivo pós-2010, os custos de manutenção estão em curso e,

Movimento, Porto Alegre, v. 20, n. 2, p. 711-733, abr.jun. de 2014. 
em certos casos, o futuro das instalações, incertos (SYLVESTER; HARJU, 2010, p. 6).

A empresa de consultoria Grant Thornton previu que 415.000 novos postos de trabalho seriam criados, embora muitos temporários (CORNELISSEN; BOB; SWART, 2011a, p. 312). Apesar da ampliação relativa deste setor, mais de um milhão de empregos foram perdidos na África do Sul em 2009 e 2010 (SYLVESTER; HARJU, 2010, p. 8). Some-se a essa análise que mais de 300.000 pessoas visitaram a África do Sul durante o evento, muito embora as projeções iniciais estimassem que seriam mais de 450.000 pessoas (CORNELISSEN; BOB; SWART, 2011a, p. 312). Isto, por sua vez, significa que o gasto dos turistas foi significativamente mais baixo que as estimativas originais. Estima-se que o evento de 2010 teve 2,5 bilhões de dólares em impostos livres para a FIFA, a Copa do Mundo mais rentável até então (DEIONNO, 2010).

O mês de realização do evento, de fato, trouxe um renovado senso de otimismo, enquanto a veiculação de uma retórica panafricanista distintiva e emotiva era evidente, especialmente na imprensa, muitas vezes impulsionada por interesses corporativos (BOLSMANN, 2012). Burawoy e Von Holdt (2012, p. 10), aponta que o evento foi "um espetáculo, se é que alguma vez houve algum que absorveu a atenção de toda a população, mascarando os reais interesses em jogo". Poucos dias após a conclusão do torneio, funcionários do Estado, incluindo enfermeiros, policiais e professores iniciaram uma greve do setor, afetando a população por um período prolongado. A greve do setor público trouxe a realidade do pós-apartheid da África do Sul. O espetáculo superou as expectativas dos organizadores locais e da FIFA. A África do Sul havia conseguido o mais ambicioso, complexo e caro megaevento a ser hospedado no continente africano na história.

Se houve um período de encanto com a realização do evento por parte dos sul-africanos, esse entusiasmo se transformou em decepção nos meses que se seguiram ao evento. Os sul-africanos questionaram as promessas feitas pelos organizadores locais e

Movimento, Porto Alegre, v. 20, n. 2, p. 711-733, abr.jun. de 2014. 
pela FIFA sobre os "legados" do evento, os custos exorbitantes e alegações de má gestão, corrupção e assassinato (COTTLE, 2011). Os reais impactos sócio-econômicos para o país foram marginais, enquanto os "legados" foram mínimos. A Copa do Mundo 2010 representou um mês de um caro festival pago pelos sul-africanos em que a FIFA colheu lucros recordes. No período de quatro anos de preparação para esse evento, essa instituição teve uma receita de US\$ 4,1 bilhões, sendo US\$ 3,89 bilhões somente relacionado ao evento de 2010, gerando um lucro de aproximadamente US\$ 600 milhões (FIFA, 2010).

\section{QUE PODEMOS RETER dA EXPERIÊnCIA dA ÁfricA do SUL?}

As contradições e tensões acima situadas sobre a realização da Copa do Mundo FIFA na África do Sul em 2010 se constituem em um alerta para a sociedade brasileira. Conforme vimos, existe uma incompatibilidade entre os discursos oficiais/extra-oficiais construídos e evocados no sentido de afirmar que o evento trouxe uma gama de benefícios para a África do Sul e sua população - e a realidade propriamente dita dos fatos. Isso, por sua vez, nos sugere que megaeventos como a Copa do Mundo FIFA (inclua-se também os Jogos Olímpicos de Verão), estão pautados na reprodução de uma série de crenças sociais que obscurecem conflitos e, acima de tudo, tornam dificultosas a compreensão de quem são os grupos esportivos, políticos e empresariais que se beneficiam mais diretamente com a realização de eventos dessa magnitude.

Tendo em vista esse cenário, e com base também no recenseamento bibliográfico apresentado na seção anterior, é permissível então dizer que a Copa do Mundo FIFA foi conduzida na sociedade sul-africana a partir de uma crença num suposto desenvolvimento social, de questionável significado conceitual e empírico. Esse tipo de crença que reporta à expansão do mercado foi particularmente eficaz nesse país porque se associou àquele quadro sentimentalista e emocional que tem regido a lógica de

Movimento, Porto Alegre, v. 20, n. 2, p. 711-733, abr.jun. de 2014. 
oferta e demanda do esporte no interior de sociedades periféricas ou "de desenvolvimento tardio". Cabe frisar que as consequências políticas deste casamento firmado entre a lógica expansionista do mercado esportivo global e a necessidade de consumo do esporte a partir de um mito nacionalista próprio, no caso da África do Sul o mito da africanidade, são deletérias, pois além de denotarem interesses particulares de grupos dominantes específicos terminam por mascarar o fato de que apenas uma parcela da população de países periféricos como a África do Sul se beneficiou diretamente ou mesmo indiretamente da realização da Copa do Mundo FIFA.

Acresça-se a essa proposta de análise que a crença desenvolvimentista que animou a gestão da Copa do Mundo de 2010 na África do Sul foi fomentada, dentre outras coisas, a partir da temática dos "legados". Nunca é demais ressaltar que os burocratas da política que investem e vivem do esporte precisam e se sentem obrigados em reproduzir o discurso dos "legados" (SOUZA; MARCHI JÚNIOR, 2010) com vistas a justificar perante a opinião pública os altos investimentos estatais feito nesses eventos ou ainda para fomentar mais e mais investidores da iniciativa privada. Por sua vez, o campo midiático a partir de uma lógica própria regulada quase que exclusivamente pelo chamado índice de audiência (BOURDIEU, 1997) tende a reverberar essa crença para sociedade organizada que, por sua vez, aceita pacificamente esse tipo de discurso ou, de forma reacionária e ativista, acaba sendo contra a realização de megaeventos como a Copa do Mundo FIFA.

Aprofundando mais no caso do evento de 2010, vimos também ser perpetuada em larga medida uma crença que denotava desconfiança com relação à capacidade do continente africano ou, mais precisamente, da África do Sul sediar esse evento no padrão FIFA. Alguns investidores e parte da mídia esportiva especializada mundial ressaltaram os problemas de desigualdade e violência nesse país. Esse discurso, no entanto, é altamente ideológico porque na medida em que se estigmatizou a África do Sul, chamando atenção para todos seus problemas sociais, na verdade se escondeu o real e principal interesse de expandir o mercado-FIFA e seus produtos

Movimento, Porto Alegre, v. 20, n. 2, p. 711-733, abr.jun. de 2014. 
e bens potencialmente consumíveis para o continente africano, independentemente dos problemas estruturais sedimentados na sua história de exploração pelo capitalismo central. Se não bastasse esse tipo de situação, a mesma ainda foi convertida em justificativa para que a África recebesse uma Copa do Mundo FIFA, afinal os "legados tangíveis" para a população sul-africana seriam inúmeros conforme se veiculou na fase de candidatura e preparação do evento, o que, no entanto, tem se demonstrado, no mínimo, questionável.

Por outro lado, vimos se cristalizar uma crença fundada em uma série de elementos patrióticos e nacionalistas destacando justamente a importância de se conferir uma oportunidade para que o continente africano pudesse realizar sua primeira Copa do Mundo. Ela serviria como "portas" e verdadeiras "vitrines" do continente africano para o mercado europeu e norte-americano, discurso incorporado tanto no projeto de candidatura de Marrocos quanto da própria África do Sul. Deste modo, é possível afirmar que pela Copa do Mundo FIFA realizada em 2010, os grupos dirigentes e de poder da África do Sul, não sem interesses específicos e particulares, procuraram vender e forjar uma imagem de africanidade muito diferente daquilo que um juízo etnocêntrico é tendente a idealizar, e pautado, portanto, no discurso da modernidade, do desenvolvimento social e do esporte como panacéia para os problemas sociais e estruturais desse continente.

Diante, portanto, desse quadro social remontado, uma primeira lição que podemos reter da experiência da África do Sul com a realização da Copa do Mundo FIFA em 2010, é que a realidade que sustenta megaeventos como esse é marcadamente diferente das razões originais, e nunca devidamente tematizadas, que movem o desejo de sediar eventos desse porte em países periféricos. Nesse sentido, os megaeventos são vistos como "valiosas oportunidades promocionais" nas quais países são mostrados para "audiências globais e ajudam a atrair turismo e investimentos externos" (HORNE, 2007, p. 83), indiferentemente dos níveis econômicos ou da posição geográfica em que eles se encontram. Mas no caso das "economias emergentes", essas inserções também se apresentam

Movimento, Porto Alegre, v. 20, n. 2, p. 711-733, abr.jun. de 2014. 
como oportunidades para enfatizar seus sucessos econômicos e relativo crescimento no contexto das relações internacionais, potencializados através de um poderio simbólico (CORNELISSEN, 2010).

Um exemplo disso que estamos dizendo pode ser verificado no discurso do então presidente da República Luiz Inácio Lula da Silva quando o Rio de Janeiro foi eleito sede dos Jogos Olímpicos e Paraolímpicos de 2016, em que a "vitória" foi classificada como a conquista da "cidadania internacional" pelo Brasil (SILVA, 2009). Entretanto, essas justificativas e estratégias para melhoria da imagem do país devem ser questionadas, já que esses eventos esportivos podem gerar imagens e discursos positivos(CULL, 2011), mas não necessariamente apagar os históricos de desigualdade e imagens negativas veiculadas internacionalmente (CARTER, 2011, MANZENREITER, 2010), conforme demonstram os casos recentes dos Jogos Olímpicos e Paraolímpicos realizados na China em 2008 e os Jogos da Comunidade Britânica sediados pela Índia em 2010.

Uma segunda lição que podemos extrair da Copa do Mundo FIFA sediada pela África do Sul em 2010 é que o Comitê Organizador Local, as elites e a grande mídia trouxeram uma série de razões para justificar o motivo de sediar grandes eventos, mas que tendencialmente se tornam retóricas nas quais a população, de maneira mais ampla, suporta o gasto de significativo montante de financiamento público nesse espetáculo de um mês de duração. Além disso, este produto a Copa do Mundo FIFA -, objetivamente falando, só foi acessível a um pequeno segmento social em detrimento de uma grande parte da população (BOLSMANN, 2012). O mercado sob o qual a FIFA opera, a exemplo do que ocorre com qualquer outra instituição/ empresa, não é neutro. Dito de outro modo, o mercado moderno sob o qual o esporte se assenta longe de ser uma instituição democrática na qual todos os agentes teriam livre acesso é perpassado por valores morais que acabam coincidindo com os interesses objetivos de alguns determinados grupos sociais enquanto marginalizam outros (SOUZA, 2006, 2011, MAGUIRE; YOUNG, 2002).

Movimento, Porto Alegre, v. 20, n. 2, p. 711-733, abr.jun. de 2014. 
É preciso, nesse caso, considerar que o mercado-FIFA, consubstanciado na figura das Copas do Mundo, não se expande para todas as direções sociais, garantindo uma mesma possibilidade de consumo para todos os estratos e grupos. No caso da Copa do Mundo FIFA na África do Sul, conforme pesquisa local, isso foi particularmente notório e visível. De acordo com Cronjé, Van Wyk, e Botha (2011), as áreas que obtiveram maiores investimentos foram aquelas com infraestrutura já desenvolvida enquanto aquelas áreas mais pobres continuaram precárias, aprofundando as diferenças já existentes. Essa situação, no caso da África do Sul, foi ainda mais agravada pelo fato que as áreas menos desenvolvidas tinham esse histórico de segregação desde o apartheid. Entretanto, ainda conforme os autores, isso não significa que a exclusão se dava pela perspectiva racial, mas porque as obras foram realizadas em função da Copa do Mundo FIFA e não para resolver os problemas locais. Essa análise, por conseguinte, pode e deve ser estendida a outras sociedades periféricas.

Finalmente, devemos lembrar que os estratos sociais menos privilegiados dos países periféricos acabam tendo acesso aos bens e produtos futebolísticos, especialmente por via da televisão. Mas esse consumo televisivo, pelo que tudo indica, já havia sido garantido à população sul-africana em outras edições da Copa do Mundo FIFA, de modo que justificar a realização e financiamento deste megaevento no referido país com dinheiro público por conta e em função do suposto retorno social e da democratização do futebol para todos os estratos que compunham esta sociedade, não passou de uma estratégia de legitimação que aponta para um benefício tardio, intangível, de difícil mensuração, cujo questionamento maior se dá após as atenções serem direcionadas ao próximo evento.

Se, portanto, é legítimo esperar que o esporte opere através da lógica do mercado e de sua expansão pelo mundo, por outro lado, é no mínimo ingênuo compactuar com a crença de que megaeventos tais como a Copa do Mundo FIFA, puderam ser consumidos da mesma forma por toda a população sul-africana, inclusive, daqueles estratos destituídos de volume suficiente de

Movimento, Porto Alegre, v. 20, n. 2, p. 711-733, abr./jun. de 2014. 
capital econômico e cultural para tal ação. Mais ingênuo e com consequências deletérias do ponto de vista político e científico é fazer dessa crença desenvolvimentista amparada no ideal de uma oferta democrática dos megaeventos esportivos, uma pseudo-razão que justifique o financiamento majoritário desses eventos pela iniciativa pública. É necessário, nesse sentido, admitir, em diálogo com Damo (2011, p. 70), que o esporte como espaço comercial deveria bancar seus próprios produtos e, no caso da Copa do Mundo FIFA na África do Sul, não foi o que ocorreu.

\section{Considerações finaIS}

A análise de casos anteriores de megaeventos esportivos denota cuidados sobre descontextualizações em diversos sentidos - temporais, sociais, econômicas e culturais - mas permite uma revisão ou, no mínimo, que se apontem razões que sugerem atenção para a preparação e realização de eventos futuros. Nesse particular, a literatura acadêmica e as informações midiáticas trazidas nas seções anteriores do texto cotejam alguns pontos que merecem um maior aprofundamento teórico. A intenção nesse momento não é tender a nenhuma espécie de "profetismo", mas, à título de fechamento, argumentar que os diversos grupos que compõe a sociedade brasileira precisam olhar para os megaeventos com cautela e, em particular, para as experiências que outras sociedades acumularam ao sediar eventos

Retomando então as fases de candidatura e de preparação da Copa do Mundo de futebol de 2010, é passível de concluir que a sociedade sul-africana viu-se envolta no discurso de que este evento traria um relativo desenvolvimento para o país, ao incentivar o investimento público e privado em diversas áreas, especialmente em infraestrutura, cujos benefícios seriam estendidos a todos os setores sociais. Mais do que isso, houve, como vimos anteriormente, uma articulação ideológica pela qual se difundiu a crença de que sediar o evento era um caminho alternativo para mostrar um novo continente e um novo país, diferente daquela

Movimento, Porto Alegre, v. 20, n. 2, p. 711-733, abr.jun. de 2014. 
imagem cristalizada sobre a África no âmbito internacional. Assim sendo, esse evento foi tido como oportunidade ímpar de abertura à modernidade normativa e ao mundo. Entretanto, mais que um significado "abstrato", essa retórica oficial também foi guiada por uma expectativa de impactos sociais, apoiados por parte da mídia.

Se, por um lado, exacerbavam-se então expectativas nacionais e locais, por outro, as instituições esportivas faziam entender que oportunizar o rodízio das sedes era uma forma de "democratizar" o "espetáculo" e difundir o futebol para outras regiões do mundo. Essa estratégia, no entanto, pode ser entendida como um meio de expandir os mercados, tanto o futebolístico como o de outros bens culturais, criando novos atrativos simbólicos para a mídia transmitir o evento, assim como para os patrocinadores. Neste particular, o que fica latente é que, como em outros países, a realização da Copa do Mundo FIFA se consolida a partir de interesses mútuos que denotam, por um lado, a expansão de mercados altamente consumidores e, por outro, a visibilidade daqueles responsáveis pelas decisões nos países-sede, que são os reais beneficiados sob o ponto de vista econômico e político.

Trazer, portanto, essas lógicas sociais à tona talvez seja um passo fundamental para interpretar as ações e os discursos que têm sido veiculados no Brasil com relação aos megaeventos esportivos. Uma série de reflexões, inclusive, já vem sendo elaboradas por autores com base no processo de seleção e preparação do país, tanto para a Copa do Mundo FIFA de 2014 quanto para os Jogos Olímpicos e Paraolímpicos de 2016 (TAVARES, 2011, DAMO, 2012, MASCARENHAS, 2012) o que, por sua vez, se trata de uma iniciativa louvável, mas que enseja de investimento sistemático e crítico por mais pesquisadores e, principalmente, um acompanhamento contínuo que, dentre outras coisas, permita avaliar a fase pré, durante e pós-realização dos megaeventos esportivos no Brasil.

Essa agenda de pesquisa aqui sugerida em diálogo com as proposições de outros autores que iniciaram esse debate na Revista

Movimento, Porto Alegre, v. 20, n. 2, p. 711-733, abr./jun. de 2014. 
Movimento é de fundamental importância para o esclarecimento de temáticas sociais e pontos de vista pouco debatidos quando senão silenciados sobre os megaeventos esportivos. Além disso, não podemos esperar que a mídia ou o governo se coloquem à frente desse projeto crítico e de esclarecimento coletivo, até porque grande parte dos agentes que integram essas duas esferas tem interesse em conservar a "realidade" e se conservarem com ela. Tampouco devemos ambicionar que a população produza, como que por "passe de mágica", as respostas mais convincentes para esses dilemas apontados. Nesse particular, concluímos e defendemos que a academia deve se colocar à frente de um projeto científico comprometido em desnaturalizar e desmascarar rigorosamente os discursos oficiais e pseudo-intelectuais sobre os megaeventos esportivos ou no mínimo tornar explícito o fato de que: "[...] sempre que a reflexividade humana não pode se expandir até a última cadeia causal que explica um fenômeno, este pode ser utilizado para fins de manipulação ideológica" (SOUZA, 2011, p. 44).

FIFA World Cup in South Africa 2010: How was this experience and what can we learn with it?

Abstract: In this essay, we intend to discuss some social logics not explicit that articulate the domain of the FIFA World Cup. Therefore, the 2010 edition of this event is used as analytical approach to reveal some of the rhetoric and strategic actions that permeated the context of its realization. Based on data obtained in the academic literature and media, we present that the motivations for the event were based on developmental discourses by both FIFA as well as local elites South African aiming to convince different social groups and conquer their support. However, the consequences are not necessarily those promised, and these institutions were the real beneficiaries in their economic and political mutual interests. At this point, we argue that Brazilian society can and should learn from the experience of South Africa to assess critically the motives less apparent to host such events.

Key-words: Mega-events. Football. FIFA World Cup. South Africa 2010.

Movimento, Porto Alegre, v. 20, n. 2, p. 711-733, abr./jun. de 2014. 


\begin{abstract}
EI Mundial FIFA Sudáfrica 2010: ¿Cómo fue la experiencia y qué es posible aprender con ella?

Resumen: En este ensayo se pretende discutir algunas lógicas sociales no explícitas que se articulan en el ámbito de la realización del Mundial de la FIFA. Por lo tanto, nos centramos como enfoque analítico la edición de 2010 de este evento, para revelar algunas de las retóricas y acciones estratégicas que impregnaran el contexto de su preparación en Sudáfrica. Con base en los datos obtenidos en la literatura académica y los medios de comunicación, se presenta como motivaciones para el evento se presentaban los discursos de desarrollo, tanto por la FIFA como por las elites locales de Sudáfrica, con el objetivo de convencer y tener el apoyo de distintos grupos sociales. Sin embargo, las consecuencias no son necesariamente las que se prometió, y estas instituciones fueron los beneficiarios reales en sus intereses económicos y políticos. En este punto, se argumenta que la sociedad brasileña puede y debe aprender con esa experiencia para evaluar críticamente los motivos menos aparentes para acoger este tipo de eventos.

Palabras clave: Mega-eventos. Fútbol. Mundial FIFA. Sudáfrica 2010.
\end{abstract}

\title{
REFERÊNCIAS
}

ALEGI, P. "Feel the pull in your soul": local agency and global trends in South Africa's 2006 World Cup bid. Soccer and Society, Abingdon (Inglaterra), v. 2, n. 3, p. 1-21, 2001.

ALEGI, P.; BOLSMANN, C. From apartheid to unity: white capital and black power in the racial integration of South African football, 1976-1992. African Historical Review, Abingdon (Inglaterra), v. 42, n. 2, p. 1-18, 2010.

ANDRANOVICH, G.; BURBANK, M.; HEYING, C. H. Olympic cities: lessons learned from mega-event politics. Journal of Urban Affairs, Malden (EUA), v. 23, n. 2, p. 113-131, 2001.

BECKENBAUER issues 2010 warning. BBC Sport, London, 20 sept. 2006. Disponível em: <http://news.bbc.co.uk/sport1/hi/football/africa/5362504.stm>. Acesso em: 13 mar. 2012.

BLACK, D.; VAN DER WESTHUIZEN, J. The allure of global games for 'semiperipheral' polities and spaces: a research agenda. Third World Quarterly, Abington (Inglaterra), v. 25, n. 7, p. 1195-1214, 2004.

Movimento, Porto Alegre, v. 20, n. 2, p. 711-733, abr./jun. de 2014. 
BOLSMANN, C. Mexico 1968 and South Africa 2010: Sombreros and Vuvuzelas and the Legitimizations of Global Sporting Events. Bulletin of Latin American Research, Malden (EUA), v. 29, n. 1, pp. 93-106, 2010.

BOLSMANN, C. Representation in the first African World Cup: 'world class', PanAfricanism, and exclusion. Soccer and Society, Abingdon (Inglaterra), v. 13, n. 2, p. 156-172, 2012.

BOURDIEU, P. Contrafogos 2. Rio de Janeiro: Zahar, 2001.

BOURDIEU, P. Contrafogos: táticas para enfrentar a invasão neoliberal. Rio de Janeiro: Zahar, 1998.

BOURDIEU, P. Sobre a televisão. Rio de Janeiro: Zahar, 1997.

BURAWOY, M.; VON HOLDT, K. Conversations with Bourdieu: the Johannesburg moment. Johannesburg: Wits University, 2012.

BURBANK, M.; ANDRANOVICH, G. D.; HEYING, C. H. Olympic dreams: the impact of mega-events on local politics. Boulder, Colorado: Lynne Rienner, 2001.

CARTER, T. Interrogating athletic urbanism: On examining the politics of the city underpinning the production of the spectacle. International Review for the Sociology of Sport, Abingdon (Inglaterra), v. 46, n. 2, p. 131-139, 2011.

COLONIAL Charlton under fire. The Guardian, Londres (Inglaterra), 23 jan. 2000, Disponível em: <http://www.guardian.co.uk/football/2000/jan/23/newsstory.sport>. Acesso em: 8 mar. 2012.

CORNELISSEN, S. “It's Africa's Turn'” The narratives and legitimations surrounding the Moroccan and South African bids for the 2006 and 2010 FIFA finals. Third World Quarterly, Abingdon (Inglaterra), v. 25, n. 7, p. 1293-1310, 2004.

CORNELISSEN, S. The geopolitics of global aspiration: Sports mega-events and emerging powers. The International Journal of the History of Sport, Abingdon (Inglaterra), v. 27, n. 16-18, p. 3008-3025, 2010.

CORNELISSEN, S.; BOB, U.; SWART, K. Sports mega-events and their legacies: The 2010 FIFA World Cup. Development Southern Africa, Abingdon (Inglaterra), v. 28 , n. 3, p. 305-306, 2011a.

CORNELISSEN, S.; BOB, U.; SWART, K. Towards redefining the concept of legacy in relation to sport mega-events: Insights from the 2010 FIFA World Cup. Development Southern Africa, Abingdon (Inglaterra), v. 28, n. 3, p. 307-318, 2011b.

CORNELISSEN, S.; SWART, K. The 2010 football World Cup as a political construct: the challenge of making good an African promise. In: HORNE, J.; MANZENREITER, W. (Ed.). Sports mega-events: social scientific analysis of global phenomenon. Oxford: Blackwell, 2006.

COTTLE, Eddie (ed.). South Africa's World Cup: a legacy for whom? UKZN: Scottsville, 2011.

Movimento, Porto Alegre, v. 20, n. 2, p. 711-733, abr.jun. de 2014. 
CRONJÉ, F.; VAN WYK, D.; BOTHA, D. The 2010 FIFA World Cup: service delivery, 'afrophobia' and brand imperialism: through the eyes of Frantz Fanon. Alternation, Durban (África do Sul), v. 17, n. 2, p. 297-322, 2011.

CULL, N. The public diplomacy of the modern Olympic Games and China's soft power strategy. In: PRICE, M.; DAYAN, D. (Ed.). Owning the Olympics: narratives of the new China. 4. ed. Ann Arbor: University of Michigan, 2011.

DAMO, A. S. O desejo, o direito e o dever: a trama que trouxe a Copa ao Brasil. Movimento, Porto Alegre, v. 18, n. 2, p. 41-81, abr./jun. 2012.

DAMO, A. S. Produção e consumo dos megaeventos esportivos: apontamentos em perspectiva antropológica. Comunicação, Mídia e Consumo, São Paulo, v. 8, n. 21, p. 67-92, 2011.

DARBY, P. Africa, football and FIFA: politics, colonialism and resistance. London: Frank Cass, 2002.

DEIONNO, P. World Cup 2010: the legacy. Disponível em: <http://m.iol.co.za/ article/view/s/9/a/14483>. Acesso em: 21 nov. 2012.

DESAI, A.; VAHED, G. World Cup 2010: Africa's turn or turn on Africa. In: ALEGI, P.; BOLSMANN, C. (Ed.). South Africa and the Global Game: football, apartheid and beyond. Abingdon: Routledge, 2010. p. 154-167.

ELLIS, R. Togo terrorist attack is threat. Daily Mail, Londres (Inglaterra), 8 jan. 2010. Disponível em: <http://www.dailymail.co.uk/sport/football/article-1241774/ Togo-terrorist-attack-threat-2010-World-Cup-finals.html\#ixzz0w71ToJbs>. Acesso em: 21 nov. 2012.

FIFA, Fédération Internationale de Football Association. Bid for World Cup 2006. In: LETTER SAFA to FIFA, 16 de setembro de 1994. Zurique, Suíça: Arquivos FIFA, 1994. South Africa Correspondence.

FIFA, Fédération Internationale de Football Association. FIFA Financial Report 2010. Disponível em: <http://www.fifa.com/mm/document/affederation/ administration/01/39/20/45/web_fifa_fr2010_eng[1].pdf>. Acesso em: 10 dez. 2012.

FIFA, Fédération Internationale de Football Association. Rotation ends in 2018. FIFA Media release, 29 oct. 2007d. Disponível em: <http://www.fifa.com/worldcup/ russia2018/organisation/media/newsid=625122/index.html>. Acesso em: 8 mar. 2012.

FOR THE GOOD of FIFA South Africa drops challenge to 2006 World Cup. CNN Sports Illustrated, 4 ago. 2000. Disponível em: <http://sportsillustrated.cnn.com/ soccer/world/news/2000/08/04/sa_fifa_ap/>. Acesso em: 13 mar. 2012.

GLANVILLE, B. The story of the World Cup: the essential companion to South Africa. London: Faber and Faber, 2010.

HAFERBURG, C. South Africa under FIFA's reign: the World Cup's contribution to urban development. Development Southern Africa, Abingdon (Inglaterra), v. 28, n. 3, p. 333-348, 2011.

Movimento, Porto Alegre, v. 20, n. 2, p. 711-733, abr./jun. de 2014. 
HORNE, J. The Four 'Knowns' of sports mega-events. Leisure Studies, Abingdon (Inglaterra), v. 26, n. 1, p. 81-96, 2007.

HUGHES, S. World Cup Machete Threat. Daily Star, Londres (Inglaterra), 5 Apr. 2010. Disponível em: <http://www.dailystar.co.uk/posts/view/129402/WORLDCUP-MACHETE-THREAT/>. Acesso em: 8 mar. 2012.

JENNINGS, A. Foul! The secret world of FIFA: bribes vote rigging and ticket scandals. London: Harper Collins, 2007.

KORTH, M.; ROLFES, M. Unsicheres Südafrika Unsichere WM 2010? Überlegungen und Erkenntnisse zur medialen Berichterstattung imVorfeld der Fußball weltmeisterschaft. In: HAFERBURG, C.; STEINBRINK, M. (Ed.). MegaEvent und Stadtentwicklung Im Globalen Süden: Die WM 2010 und ihre Impulse für Südafrika. Frankfurt am Main: Brandes \& Apsel, 2010. p. 96-116.

LENSKYJ, H. The best Olympics ever? Social impacts of Sydney 2000. Albany, NY: Suny, 2002.

LENSKYJ, H. Inside the Olympic industry: power, politics and activism. Albany, NY: Suny, 2000.

LENSKYJ, H. The Olympic industry and civil liberties: the threat to free speech and freedom of assembly. Sport in Society, Abingdon (Inglaterra), v. 7, n. 3, p. 370-384, 2004.

LENSKYJ, H. When winners are losers: Toronto and Sydney buds for the Summer Olympics. Journal of Sport and Social Issues, Boston (EUA), v. 24, n. 4, p. 392410, 1996.

LEWIS, D. Fears over World Cup safety. Daily Mirror, Londres (Inglaterra), 8 de janeiro de 2010. Disponível em: <http://www.mirrorfootball.co.uk/news/Fears-over-World-Cupsafety-after-gun-attack-on-Togo-bus-article281893.html>. Acesso em: 8 mar. 2012.

MAGUIRE, J.; YOUNG, K. Theory, sport \& society. New York, NY: Elsevier Science, 2002.

MANZENREITER, W. The Beijing games in the western imagination of China: the weak power of soft power. Journal of Sport and Social Issues, Boston (EUA), v. 34 , n. 1, p. 29-48, 2010.

MASCARENHAS, F. Megaeventos esportivos e educação física: alerta de tsunami. Movimento, Porto Alegre, v. 18, n. 1, p. 39-67, jan./mar. 2012.

MCKINLEY, D. T. Mbombela. Corruption, murder, false promises and resistance. In: COTTLE, Eddie (Ed.). South Africa's World Cup: a legacy for whom? UKZN: Scottsville, 2011.

MIAH, A.; GARCÍA, B. The Olympics: the basics. New York, NY: Routledge, 2012.

MOYO, P. No one wants to air 2010 documentary. Mail \& Guardian, Johanesburgo (África do Sul), 14-20 July 2010.

Movimento, Porto Alegre, v. 20, n. 2, p. 711-733, abr.jun. de 2014. 
NAURIGHT, J. Global games: culture, political economy and sport in the globalised world of the 21st century. Third World Quarterly, Abingdon (Inglaterra), v. 25, n. 2, p. 1325-1336, 2004.

NTLOKO, M. Blatter effusive in praise. Business Day, Johanesburgo (África do Sul), 13 July 2010.

PANK, P. Delays and crime threaten. The Times, Londres, 14 June 2008. Disponível em: $\quad<$ http://www.timesonline.co.uk/tol/sport/football/international/article4133483. ece>. Acesso em: 8 mar. 2012.

REIS, H. H. B. Lei geral da copa, álcool e o processo de criação da legislação sobre violência. Movimento, Porto Alegre, v. 18, n. 1, p. 69-99, jan./mar. 2012.

SATURDAY STAR. KeNako: we have arrived! Saturday Star, Johanesburgo (África do Sul), p. 16, 12 June 2010.

SEFARA, M. Why must we, of all people, be like this? The Sunday Independent, Johanesburgo (África do Sul), p. 14, 11 July 2010.

SILVA, L. I. L. Entrevista coletiva concedida a jornalistas brasileiros e estrangeiros pelo Presidente da República, Luiz Inácio Lula da Silva, após o anúncio da escolha da cidade-sede dos Jogos Olímpicos de 2016. Copenhagen, Dinamarca, 2 out. 2009. Disponível em: <http://www.itamaraty.gov.br/sala-de-imprensa/discursosartigos-entrevistas-e-outras-comunicacoes/presidente-da-republica-federativa-dobrasil/entrevista-coletiva-concedida-a-jornalistas>. Acesso em: 12 dez. 2012.

SINDANE, L. Decade of a Dream. Mail \& Guardian, Johanesburgo (África do Sul), 30 may 2008. Disponível em: <http://mg.co.za/article/2008-05-30-decade-of-adream>. Acesso em: 21 nov. 2012.

SMITH, D. Life in Tin Can Town for Those Evicted Ahead of World Cup. Mail \& Guardian, Johanesburgo (África do Sul), 2 apr. 2010. Disponível em: <http://www. mg.co.za/article/2010-04-02-life-in-tin-can-town-for-those-evicted-ahead-of-worldcup>. Acesso em: 8 mar. 2012.

SOUTH AFRICA after the World Cup: Is there a lot more to come? The Economist, Londres (Inglaterra), 15 July 2010. Disponível em: <http://www.economist.com/ node/16595089>. Acesso em: 21 nov. 2012.

SOUZA, J. A invisibilidade da desigualdade brasileira. Belo Horizonte: Editora da UFMG, 2006.

SOUZA, J. A ralé brasileira: quem é e como vive. Belo Horizonte: Editora da UFMG, 2011.

SOUZA, J.; MARCHI JÚNIOR, W. Os "legados" dos megaeventos esportivos no Brasil: algumas notas e reflexões. Motrivivência, Florianópolis, v. 22, n. 34, p. 245-255, jun. 2010.

SOWETAN. Congratulations to ourselves. Sowetan, Johanesburgo (África do Sul), 14 may 2004.

Movimento, Porto Alegre, v. 20, n. 2, p. 711-733, abr./jun. de 2014. 
SUGDEN, J.; TOMLINSON, A. FIFA and the contest for world football: who rules the peoples' game. Cambridge: Polity, 1998.

SYLVESTER, J.; HARJU, D. What's left after the World Cup? ePoliticsSA, Johanesburgo (África do Sul), v. 1, p. 2-22, 2010.

TAVARES, O. Megaeventos esportivos. Movimento, Porto Alegre, v. 17, n. 3, p. 11-35, jul./set. 2011.

THE DAY we won respect. The Sunday Independent, Johanesburgo (África do Sul), p. 6-7, 13 June 2010.

TOLSI, N. Field of Shattered Dreams. Mail \& Guardian, Johanesburgo (África do Sul), 7 may 2010. Disponível em: <http://www.mg.co.za/article/2010-05-07-field-ofshattered-dreams>. Acesso em: 18 jul. 2012.

TOMLINSON, R.; BASS, O.; PILLAY, U. Introduction. In: TOMLINSON, R.; BASS, O.; PILLAY, U. (Ed.). Development and dreams: the urban legacy of the 2010 football World Cup. Cape Town: HSRC, 2009.

Endereço para correspondência:

Prof. Dr. Wanderley Marchi Júnior

Centro de Pesquisa em Esporte, Lazer e Sociedade (CEPELS)

Rua Coração de Maria, 92 - Jardim Botânico

Curitiba - PR - Brasil

CEP 80215-370 